\title{
Integration of Lot Sizing and Flow Shop Scheduling with Lot Streaming
}

\author{
Navid Mortezaei and Norzima Zulkifli \\ Department of Mechanical and Manufacturing Engineering, Universiti Putra Malaysia, 43400 Serdang, Selangor, Malaysia \\ Correspondence should be addressed to Navid Mortezaei; navidmortezae@yahoo.com
}

Received 26 May 2013; Revised 15 September 2013; Accepted 2 October 2013

Academic Editor: Yuri Sotskov

Copyright ( 2013 N. Mortezaei and N. Zulkifli. This is an open access article distributed under the Creative Commons Attribution License, which permits unrestricted use, distribution, and reproduction in any medium, provided the original work is properly cited.

\begin{abstract}
We will develop a mathematical model for the integration of lot sizing and flow shop scheduling with lot streaming. We will develop a mixed-integer linear model for multiple products lot sizing and lot streaming problems. Mixed-integer programming formulation is presented which will enable the user to find optimal production quantities, optimal inventory levels, optimal sublot sizes, and optimal sequence simultaneously. We will use numerical example to show practicality of the proposed model. We test eight different lot streaming problems: (1) consistent sublots with intermingling, (2) consistent sublots and no intermingling between sublots of the products (without intermingling), (3) equal sublots with intermingling, (4) equal sublots without intermingling, (5) nowait consistent sublots with intermingling, (6) no-wait equal sublots with intermingling, (7) no-wait consistent sublots without intermingling, and (8) no-wait equal sublots without intermingling. We showed that the best makespan can be achieved through the consistent sublots with intermingling case.
\end{abstract}

\section{Introduction}

In the manufacturing industries, the commonly used planning and scheduling decision-making strategy generally follows a hierarchical approach, in which the planning problem is solved first to define the production targets, and the scheduling problem is solved next to meet these targets [1]. However, this traditional strategy presents a great disadvantage, since there is no interaction between the two decision levels; that is, the planning decisions generated might cause infeasible scheduling subproblems [1]. Since the production planning model ignores detailed scheduling constraints, there is no guarantee that a feasible production schedule exists for the generated production plan. Typically, when infeasibilities are discovered, ad hoc adjustments are made within the production plan [2]. Therefore, it is necessary to develop methodologies that can effectively integrate production planning and scheduling. Potts and Van Wassenhove [3] reviewed studies in which either batching or lotsizing decisions along with scheduling decisions were made, and they concluded that not much research has been conducted in this area. We summarize some works of research regarding integration of lot sizing and flow shop scheduling as follows. Riane et al. [4] considered production planning and scheduling simultaneously in hybrid flow shop organizations (also called flexible flow shop). The solution approach adapted in their paper was "divide and conquer," consisting of decomposing the problem into a loading problem, a batching problem, and a scheduling problem. Yan et al. [5] developed an integrated production planning and scheduling model for automobile assembly lines. In this case, hierarchical production planning approaches have been used to decompose monthly or weekly plans into day or shift plans. They solved first production planning model and then solved the scheduling problem by dispatching rules (EDD and smallest lots); if there are not feasible solutions, the neighbors plan and neighbor schedule definitions will be used to find feasible initial solutions [5]. They proposed three tabu search algorithms that explore solution spaces for both problems and found a combination of a production plan and schedule that are feasible and that approximately optimize the objective function. Palaniappan and Jawahar [6] developed a model for simultaneous optimization of lot sizing and scheduling in a flow line assembly. Procurement lot 
sizing and production scheduling are considered to be the two critical factors in controlling the cost of production in those units. The simultaneous optimization of procurement lot sizing and the assembly scheduling offer many benefits. Palaniappan and Jawahar [6] claimed that only a little consideration is given to set up time-dependent production systems with order backlog. Therefore, an integrated cost model including setup time dependency and order backlog was developed to handle both procurement lot sizing and production scheduling simultaneously. They proposed a genetic algorithm (GA) based heuristic to create an optimal or near-optimal solution for the flow line assembly problem under the setup-dependent environment [6]. The objective of their model was the minimization of total cost, which includes assembly, switchover, procurement, inventory, and order backlog/shortage costs. Yan and Zhang [7] developed an integrated model for production planning and scheduling in a three-stage manufacturing system (full-space method). They claimed that most of the literature focuses on the master production schedule (MPS) and capacity requirement planning (CRP) in a manufacturing resource planning (MRPII) environment, while the scheduling problem is seldom considered [7]. Since these methods keep planning separate from scheduling, they often generate an infeasible production plan which has to be modified to obtain feasible schedule because it did not consider the details of the scheduling problem [7]. Considering production planning and scheduling simultaneously is advisable to avoid an infeasible solution. Also, Yan and Zhang claimed that none of the existing literature involves a monolithic optimization model for production planning and scheduling in a multistage system. They formulated a monolithic optimization model for a three-stage manufacturing system that includes a job shop, a parallel flow shop, and a single machine shop. Ng et al. [8] and Matsveichuk et al. [9] considered flow shop scheduling problems with interval processing times. However, none of the previous scholars considered the lot streaming problem within their models.

Lundrigan [10] summarized nine rules of optimized production technology (OPT), among which the seventh rule states that a transfer batch (i.e., a sublot) may not, and often should not, be equal to a processing batch (i.e., a lot). Clearly, lot streaming is a technique for splitting jobs, each consisting of identical items, into sublots to allow their overlapping on successive machines in multistage production systems. In this way, production can be accelerated, and a remarkable reduction of makespan and improved timeliness are within reach [11]. Generally, the goal in lot streaming is to determine the number of sublots for each product, the size of each sublot, and the sequence for processing the sublots so that a given objective is optimized $[12,13]$. The following terms summarize different directions of lot streaming research; see Feldmann and Biskup [12], Kalir and Sarin [14], Sarin and Jaiprakash [15], and Zhang et al. [13].

Single Product/Multiple Products. Either a single product or multiple products are considered.

Fixed/Equal/Consistent/Variable Sublots. Fixed sublots mean that all sublots for all products consist of an identical number of items on all stages. Equal sublots refer to the case when all the sublots of a lot are of the same size. When identical sublot sizes are used to transfer a lot between every pair of consecutive machines, the sublots are termed consistent. However, if the sublot sizes used for transferring a lot among the machines vary, the sublots are called variable $[12,14]$.

Discrete/Continuous Sublots. The sublots of a lot are, in general, assumed to take real-valued (continuous) sizes. However, integer sublot sizes are more relevant for the manufacturing facilities involved in the production of discrete parts $[13,14]$. Examples for both cases include books, cars, and furniture, which require integer variables, while for the production (not the sizing) of gas, beverages, concrete, electricity, and so forth real variables are appropriate [12].

Non-Idling/Intermitted Idling. No idling refers to the situation where no idle time is permitted between the processing of the sublots of a lot on a machine. Under intermittent idling, an idle time may be present between the processing of two successive sublots of a lot on a machine [15].

No-Wait/Wait Schedules. In a no-wait flow shop, each sublot of a lot is processed continuously on all the machines. This could lead to an inserted idle time before the processing of a sublot of a lot on a machine. In a wait schedule, a sublot may wait for processing between consecutive stages [15].

Attached Setups/Detached Setups/No Setups. If attached setups are needed, the setup cannot begin until the sublot is available at the particular stage. In a detached setup, the setup is independent from the availability of the sublot. Sometimes, setup times are neglected or do not occur [14].

Intermingling/Nonintermingling Sublots. If, in a multiproduct setting, intermingling sublots are allowed, the sequence of sublots of product $j$ may be interrupted by sublots of product $k$. For nonintermingling sublots, no interruption in the sequence of sublots of a product is allowed [12].

In the following section, we summarize research on lot streaming problems and focus on the flow shop environment.

Trietsch and Baker [16] developed a linear formulation for a single product lot streaming problem with consistent sublots. Biskup and Feldmann [17] presented the first integer programming formulation for the single product lot streaming problem with variable sublots. Chang and Chiu [18] and Chui et al. [19] show the diminishing marginal effect of lot streaming. They found that, under the same sublot type, although increasing number of sublots will reduce makespan, the marginal reduction in makespan will decrease with the increase of the number of sublots. For the flow shop, Potts and Baker [20] used a simple two-machine numerical example to show that, in the intermingled case, an optimal solution generally cannot be found when the sequencing approach and the splitting approach are used independently. They suggested that the two approaches should be used simultaneously. Glass and Possani [21] indicated that, for jobs with identical processing times and number of sublots, no advantage is obtained by allowing inconsistency 


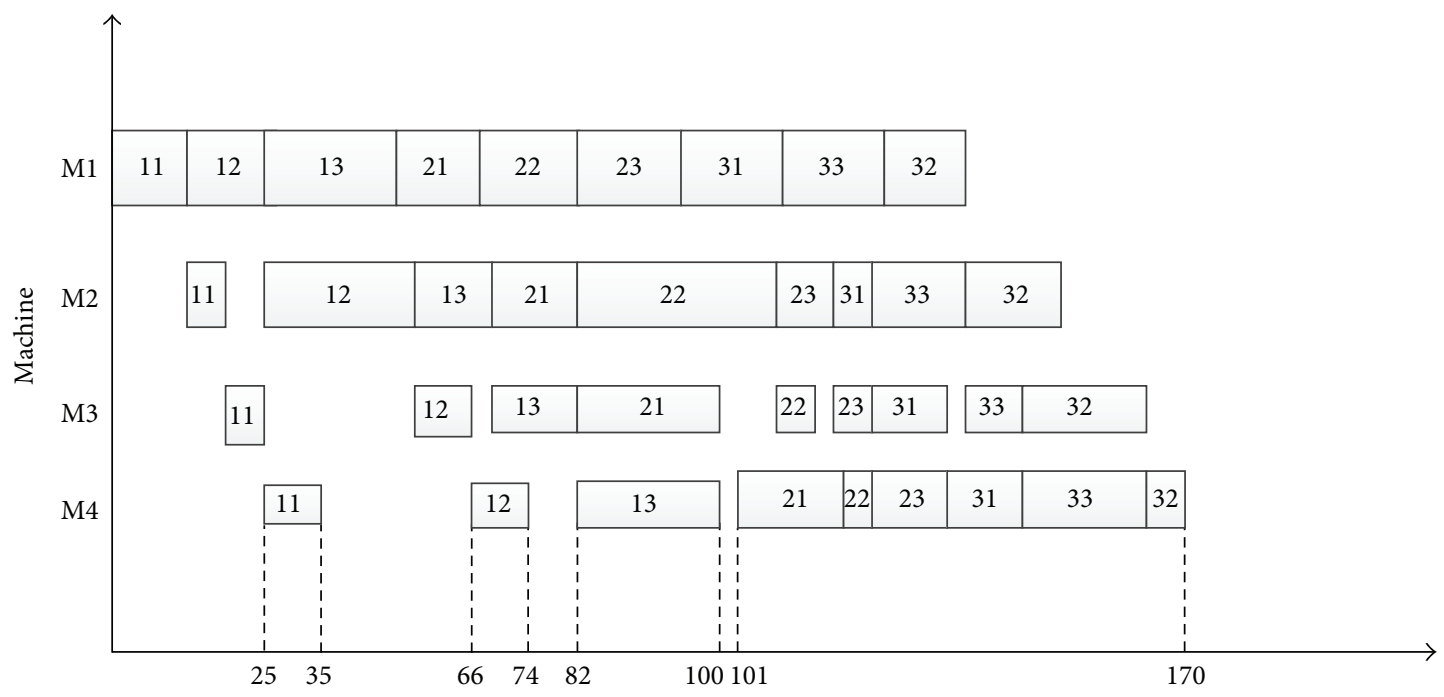

FIGURE 1: Optimal solutions of example with intermingling integer consistent sublots.

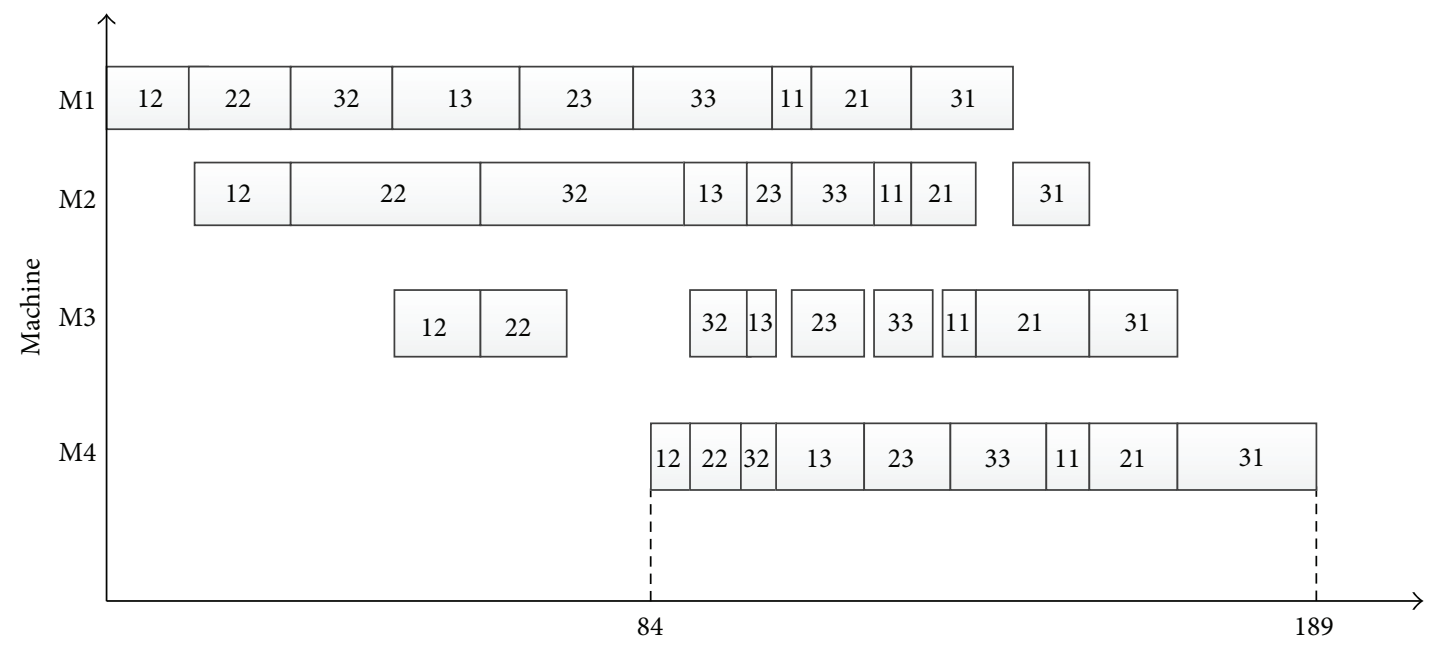

FIGURE 2: Optimal solutions of example without intermingling integer consistent sublots.

in sublot sizing of consecutive jobs. Feldmann and Biskup [12] developed a mathematical model for multiproduct lot streaming problem. They revealed that the benefit of lot streaming in multistage settings increases not only with the number of sublots but also with a growing number of stages. Tseng and Liao [22] proposed a swarm optimization procedure not only for the flow shop environment, but also for minimizing total weighted tardiness and earliness, with equally sized sublots. Marimuthu et al. [23] suggested an evolutionary algorithm approach for the multimachine lot streaming problem to minimize the total flow time and makespan with set-up times. However, all lot streaming research assumes that the number of identical items of the product on each machine is given in advance. In other words, the lot sizing problem is not integrated into lot streaming problem. In this research, we will develop a mixed-integer linear mathematical model for the integration of lot sizing and scheduling with lot streaming problem. This model can be used in medium to high volume systems such as autos, personal computers, radios and televisions, and furniture. This paper is organized as follows: Section 2 introduces the problem and develops a mathematical formulation for this problem. Implementation of this model (through an example) is given in Section 3. Finally, Section 4 gives some conclusions and suggestions for further studies.

\section{Integrated Model for Lot Sizing and Scheduling with Lot Streaming}

Brucker et al. revealed that there exists a polynomial algorithm for any regular optimization criterion in the case of two jobs while the problem with three jobs is NP-hard for any criterion traditionally considered in scheduling theory [24]. Therefore, the problem under consideration certainly is $N P$-hard. With the following model formulation, generally 


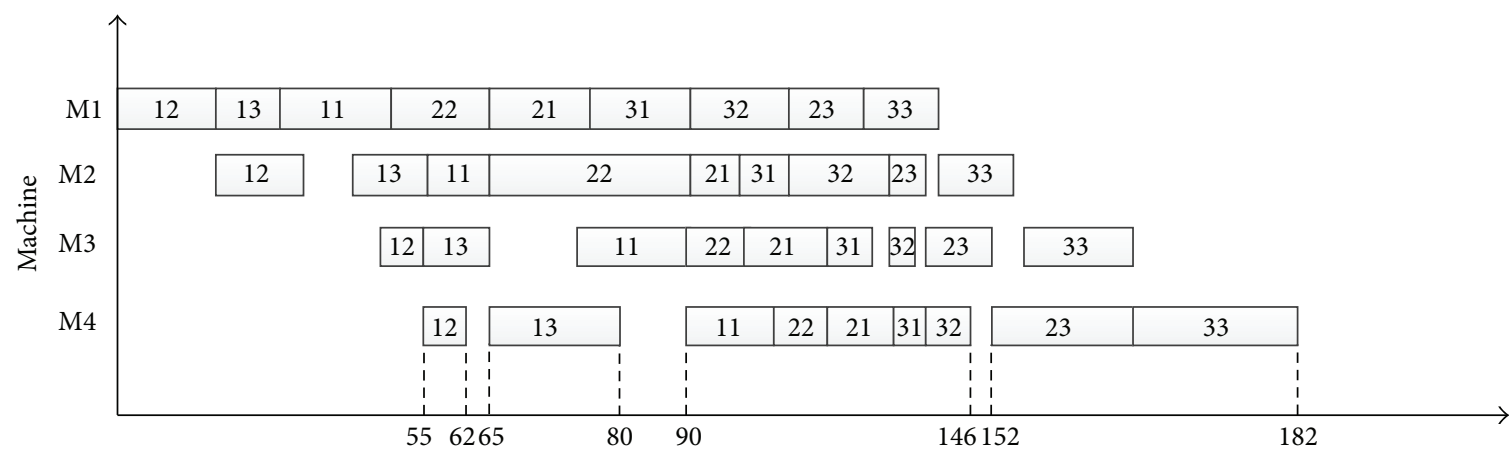

FIGURE 3: Optimal solutions of example with intermingling integer equal sublots.



FIGURE 4: Optimal solutions of example without intermingling integer equal sublots.

TABLE 1: Processing times of jobs on machines.

\begin{tabular}{llcll}
\hline \multirow{2}{*}{ Product } & \multicolumn{4}{c}{ Machine number } \\
& 1 & 2 & 3 & 4 \\
\hline 1 & 2 & 1 & 2 & 2 \\
2 & 2 & 4 & 1 & 1 \\
3 & 4 & 2 & 2 & 3 \\
\hline
\end{tabular}

speaking, the four inherent goals of the problem, namely, determining the sequence among the sublots, the size of the each lot, inventory levels, and the size of the individual sublots, are solved simultaneously. The model assumptions are as follows.

(1) All lots are available at time zero.

(2) The machine configuration considered constitutes a flow shop.

(3) Any breakdowns and scheduled maintenance are not allowed.

(4) Set-up times between operations are negligible or include processing times.

(5) There are no precedence constraints among the products.

(6) $N$ distinct final products are produced by the shop.

(7) The demand is always satisfied (no backlogging).
(8) There is an external demand for finished products (processed by last machine).

(9) All machines have capacity constraints.

(10) Planning horizon is a single period (i.e., a day).

(11) All programming parameters are deterministic and there is no randomness.

(12) An idle time may be present between the processing of two successive sublots of a lot on a machine (intermittent idling).

(13) Consistent and equal sublots are considered (no variable sublots).

(14) The number of sublots for all lots is known in advance.

This problem with above-mentioned assumptions can be formulated as follows.

Indices

$N$ : the number of products,

$M$ : the number of nonidentical machines,

$S$ : the number of sublots,

$j, v$ : indices for products $j, v=1,2, \ldots, N$,

$k$ : denotes $k$ th machine $k=1,2, \ldots, M$,

$s, z$ : indices for sublots $s, z=1,2, \ldots, S$. 
TABLE 2: Sublot completion times on different machines in consistent sublots with intermingling setting.

\begin{tabular}{lccccccccc}
\hline Machine number & $C_{11}$ & $C_{21}$ & $C_{31}$ & $C_{12}$ & $C_{22}$ & $C_{32}$ & $C_{13}$ & $C_{23}$ & $C_{33}$ \\
\hline 1 & 10 & 68 & 110 & 26 & 82 & 140 & 50 & 98 & 130 \\
2 & 15 & 82 & 126 & 58 & 110 & 160 & 70 & 118 & 140 \\
3 & 25 & 100 & 138 & 66 & 117 & 165 & 82 & 126 & 150 \\
4 & 35 & 119 & 150 & 74 & 126 & $\mathbf{1 7 0}$ & 100 & 138 & 165 \\
\hline
\end{tabular}

TABLE 3: Sublot completion times on machines for different cases.

\begin{tabular}{|c|c|c|c|c|c|c|c|c|c|c|}
\hline Case name & $\begin{array}{l}\text { Machine } \\
\text { number }\end{array}$ & $C_{11}$ & $C_{21}$ & $C_{31}$ & $C_{12}$ & $C_{22}$ & $C_{32}$ & $C_{13}$ & $C_{23}$ & $C_{33}$ \\
\hline \multirow{4}{*}{ Equal sublots with intermingling } & 1 & 48 & 76 & 90 & 14 & 62 & 104 & 34 & 127 & 147 \\
\hline & 2 & 62 & 97 & 104 & 42 & 90 & 132 & 55 & 142 & 157 \\
\hline & 3 & 90 & 111 & 125 & 55 & 97 & 139 & 65 & 152 & 167 \\
\hline & 4 & 104 & 125 & 139 & 62 & 111 & 146 & 80 & 167 & 182 \\
\hline \multirow{4}{*}{ Equal sublots without intermingling } & 1 & 116 & 130 & 144 & 14 & 28 & 42 & 62 & 82 & 102 \\
\hline & 2 & 137 & 144 & 151 & 42 & 70 & 98 & 108 & 118 & 128 \\
\hline & 3 & 163 & 177 & 191 & 49 & 101 & 108 & 118 & 133 & 148 \\
\hline & 4 & 177 & 191 & 205 & 101 & 108 & 115 & 133 & 148 & 163 \\
\hline \multirow{4}{*}{$\begin{array}{l}\text { No-wait consistent sublots with } \\
\text { intermingling }\end{array}$} & 1 & 12 & 24 & 40 & 54 & 96 & 136 & 82 & 124 & 164 \\
\hline & 2 & 18 & 30 & 48 & 82 & 124 & 160 & 96 & 136 & 168 \\
\hline & 3 & 30 & 42 & 64 & 89 & 131 & 166 & 110 & 148 & 172 \\
\hline & 4 & 42 & 54 & 80 & 96 & 138 & 172 & 131 & 166 & 178 \\
\hline \multirow{4}{*}{$\begin{array}{l}\text { No-wait equal sublots with } \\
\text { intermingling }\end{array}$} & 1 & 56 & 70 & 146 & 14 & 104 & 160 & 42 & 90 & 132 \\
\hline & 2 & 63 & 77 & 153 & 42 & 132 & 188 & 56 & 100 & 142 \\
\hline & 3 & 77 & 91 & 167 & 49 & 139 & 195 & 62 & 110 & 152 \\
\hline & 4 & 91 & 105 & 181 & 56 & 146 & 202 & 77 & 125 & 167 \\
\hline \multirow{4}{*}{$\begin{array}{l}\text { No-wait consistent sublots without } \\
\text { intermingling }\end{array}$} & 1 & 12 & 26 & 40 & 50 & 70 & 90 & 130 & 152 & 171 \\
\hline & 2 & 18 & 33 & 47 & 70 & 90 & 130 & 142 & 162 & 179 \\
\hline & 3 & 30 & 47 & 61 & 75 & 95 & 140 & 154 & 172 & 187 \\
\hline & 4 & 42 & 61 & 75 & 80 & 100 & 150 & 172 & 187 & 199 \\
\hline \multirow{4}{*}{$\begin{array}{l}\text { No-wait equal sublots without } \\
\text { intermingling }\end{array}$} & 1 & 74 & 88 & 102 & 116 & 144 & 172 & 20 & 40 & 60 \\
\hline & 2 & 81 & 95 & 109 & 144 & 172 & 200 & 30 & 50 & 70 \\
\hline & 3 & 95 & 109 & 123 & 151 & 179 & 207 & 40 & 60 & 80 \\
\hline & 4 & 109 & 123 & 137 & 158 & 186 & 214 & 55 & 75 & 95 \\
\hline
\end{tabular}

\section{Decision Variables}

$x_{s j z v}$ : binary variable, which takes the value 1 if sublot $s$ of product $j$ is sequenced prior to sublot $z$ of product $v, 0$ otherwise,

$c_{s j k}$ : completion time of sublot $s$ of product $j$ on machine $k$,

$p_{j k}$ : quantity of product $j$ produced in machine $k$,

$s_{j k}$ : stock of product $j$ after operation in machine $k$,

$c_{\text {max }}$ : maximum completion time on machine $M$ (makespan),

$u_{s j k}$ : sublot size of $s$ th sublot of product $j$ on machine $k$.

\section{Parameters and Constants}

$\mathrm{bi}_{M}$ : beginning inventory of product on machine $M$, $\mathrm{cp}_{j k}$ : production cost of product $j$ in machine $k$,

$h_{j k}:$ holding cost of product $j$,

$\mathrm{Ac}_{k}$ : available capacity of machine $k$ (measured in time units),

$d_{j}$ : external demand for product $j$ at the end of period (a day),

$\mathrm{pt}_{j k}$ : processing time for one unit of product $j$ on machine $k$,

$D$ : is used to convert the makespan into a cost (cost per unit time),

$R$ : large number. 
TABLE 4: Sublot sizes for different cases.

\begin{tabular}{|c|c|c|c|c|c|c|}
\hline $\begin{array}{l}\text { Sublot } \\
\text { name }\end{array}$ & $\begin{array}{l}\text { Equal sublots } \\
\text { with } \\
\text { intermingling }\end{array}$ & $\begin{array}{l}\text { Equal sublots } \\
\text { without } \\
\text { intermingling }\end{array}$ & $\begin{array}{l}\text { No-wait consistent } \\
\text { sublots with } \\
\text { intermingling }\end{array}$ & $\begin{array}{l}\text { No-wait equal } \\
\text { sublots with } \\
\text { intermingling }\end{array}$ & $\begin{array}{l}\text { No-wait consistent } \\
\text { sublots without } \\
\text { intermingling }\end{array}$ & $\begin{array}{r}\text { No-wait equal } \\
\text { sublots without } \\
\text { intermingling }\end{array}$ \\
\hline$u_{111}$ & 7 & 7 & 6 & 7 & 6 & 7 \\
\hline$u_{112}$ & 7 & 7 & 6 & 7 & 6 & 7 \\
\hline$u_{113}$ & 7 & 7 & 6 & 7 & 6 & 7 \\
\hline$u_{114}$ & 7 & 7 & 6 & 7 & 6 & 7 \\
\hline$u_{211}$ & 7 & 7 & 6 & 7 & 7 & 7 \\
\hline$u_{212}$ & 7 & 7 & 6 & 7 & 7 & 7 \\
\hline$u_{213}$ & 7 & 7 & 6 & 7 & 7 & 7 \\
\hline$u_{214}$ & 7 & 7 & 6 & 7 & 7 & 7 \\
\hline$u_{311}$ & 7 & 7 & 8 & 7 & 7 & 7 \\
\hline$u_{312}$ & 7 & 7 & 8 & 7 & 7 & 7 \\
\hline$u_{313}$ & 7 & 7 & 8 & 7 & 7 & 7 \\
\hline$u_{314}$ & 7 & 7 & 8 & 7 & 7 & 7 \\
\hline$u_{121}$ & 7 & 7 & 7 & 7 & 5 & 7 \\
\hline$u_{122}$ & 7 & 7 & 7 & 7 & 5 & 7 \\
\hline$u_{123}$ & 7 & 7 & 7 & 7 & 5 & 7 \\
\hline$u_{124}$ & 7 & 7 & 7 & 7 & 5 & 7 \\
\hline$u_{221}$ & 7 & 7 & 7 & 7 & 5 & 7 \\
\hline$u_{222}$ & 7 & 7 & 7 & 7 & 5 & 7 \\
\hline$u_{223}$ & 7 & 7 & 7 & 7 & 5 & 7 \\
\hline$u_{224}$ & 7 & 7 & 7 & 7 & 5 & 7 \\
\hline$u_{321}$ & 7 & 7 & 6 & 7 & 10 & 7 \\
\hline$u_{322}$ & 7 & 7 & 6 & 7 & 10 & 7 \\
\hline$u_{323}$ & 7 & 7 & 6 & 7 & 10 & 7 \\
\hline$u_{324}$ & 7 & 7 & 6 & 7 & 10 & 7 \\
\hline$u_{131}$ & 5 & 5 & 7 & 5 & 6 & 5 \\
\hline$u_{132}$ & 5 & 5 & 7 & 5 & 6 & 5 \\
\hline$u_{133}$ & 5 & 5 & 7 & 5 & 6 & 5 \\
\hline$u_{134}$ & 5 & 5 & 7 & 5 & 6 & 5 \\
\hline$u_{231}$ & 5 & 5 & 6 & 5 & 5 & 5 \\
\hline$u_{232}$ & 5 & 5 & 6 & 5 & 5 & 5 \\
\hline$u_{233}$ & 5 & 5 & 6 & 5 & 5 & 5 \\
\hline$u_{234}$ & 5 & 5 & 6 & 5 & 5 & 5 \\
\hline$u_{331}$ & 5 & 5 & 2 & 5 & 4 & 5 \\
\hline$u_{332}$ & 5 & 5 & 2 & 5 & 4 & 5 \\
\hline$u_{333}$ & 5 & 5 & 2 & 5 & 4 & 5 \\
\hline$u_{334}$ & 5 & 5 & 2 & 5 & 4 & 5 \\
\hline
\end{tabular}

Consider,

$$
\begin{gathered}
Z=\sum_{j=1}^{N} \sum_{k=1}^{M} \mathrm{cp}_{j k} p_{j k}+\sum_{j=1}^{N} \sum_{k=1}^{M} h_{j k} s_{j k}+D \times c_{\max } \\
d_{j}=p_{j M}-s_{j M}+\mathrm{bi}_{M} \quad j=1, \ldots, N, \\
\sum_{j=1}^{N} \mathrm{pt}_{j k} p_{j k} \leq \mathrm{Ac}_{k} \quad k=1, \ldots, M, \\
c_{\max } \geq c_{s j M} \quad s=1, \ldots, S, j=1, \ldots, N,
\end{gathered}
$$

$$
\begin{array}{r}
\sum_{s=1}^{S} u_{s j k}=p_{j k} \quad j=1, \ldots, N, k=1, \ldots, M, \\
u_{s j k}=u_{s j(k+1)} \quad \begin{array}{r}
\quad=1, \ldots, S, \quad j=1, \ldots, N, \\
k=1, \ldots, M-1,
\end{array} \\
c_{s j k}-\mathrm{pt}_{j k} \times u_{s j k} \geq c_{s j(k-1)} \\
\begin{array}{r}
s=1, \ldots, S, \quad j=1, \ldots, N, \quad k=2, \ldots, M, \\
c_{s j k}-\mathrm{pt}_{j k} \times u_{s j k} \geq c_{(s-1) j k} \\
s=2, \ldots, S, \quad j=1, \ldots, N, \quad k=1, \ldots, M,
\end{array}
\end{array}
$$


TABLE 5: Results of these eight different lot streaming problems.

\begin{tabular}{|c|c|c|c|c|c|}
\hline Classification & Optimal sequence & Makespan & $\begin{array}{l}\text { Objective } \\
\text { function }(z)\end{array}$ & $\begin{array}{l}\text { Comparison of } \\
\text { total cost }(z)\end{array}$ & $\begin{array}{l}\text { Comparison } \\
\text { of makespan }\end{array}$ \\
\hline $\begin{array}{l}\text { Consistent sublots with } \\
\text { intermingling }\end{array}$ & $\begin{array}{c}11-12-13-21-22-23- \\
31-33-32 \\
\end{array}$ & 170 & 3570 & - & - \\
\hline $\begin{array}{l}\text { Consistent sublots without } \\
\text { intermingling }\end{array}$ & $2-3-1$ & 189 & 3665 & $2 / 66 \%$ & $11 \%$ \\
\hline Equal sublots with intermingling & $\begin{array}{c}12-13-11-22-21-31- \\
32-23-33\end{array}$ & 182 & 3737 & $4 / 67 \%$ & $7 \%$ \\
\hline Equal sublots without intermingling & $2-3-1$ & 205 & 3852 & $7 / 9 \%$ & $20 \%$ \\
\hline $\begin{array}{l}\text { No-wait consistent sublots with } \\
\text { intermingling }\end{array}$ & $\begin{array}{c}11-21-31-12-13-22- \\
23-32-33 \\
\end{array}$ & 178 & 3610 & $1 / 12 \%$ & $4 / 7 \%$ \\
\hline $\begin{array}{l}\text { No-wait equal sublots with } \\
\text { intermingling }\end{array}$ & $\begin{array}{c}\text { 12-13-11-21-23-22- } \\
33-31-32 \\
\end{array}$ & 202 & 3837 & $7 / 47 \%$ & $18 / 8 \%$ \\
\hline $\begin{array}{l}\text { No-wait consistent sublots without } \\
\text { intermingling }\end{array}$ & $1-2-3$ & 199 & 3715 & $4 / 06 \%$ & $17 \%$ \\
\hline $\begin{array}{l}\text { No-wait equal sublots without } \\
\text { intermingling }\end{array}$ & $3-1-2$ & 214 & 3897 & $9 / 15 \%$ & $25 / 8 \%$ \\
\hline
\end{tabular}

$$
\begin{gathered}
c_{z v k}-\mathrm{pt}_{v k} \times u_{v z k}-c_{s j k}+R\left(1-x_{s j z v}\right) \geq 0 \\
j, v=1, \ldots, N \quad s, z=1, \ldots, S \\
\text { if } v=j, \quad \text { then } z \neq s, \quad k=1, \ldots, M \\
c_{s j k}-\mathrm{pt}_{j k} \times u_{s j k}-c_{z v k}+R \times x_{s j z v} \geq 0 \\
j, v=1, \ldots, N \quad s, z=1, \ldots, S \\
\text { if } v=j, \quad \text { then } z \neq s, \quad k=1, \ldots, M, \\
c_{s j 1}-\mathrm{pt}_{j 1} \times u_{s j 1} \geq 0 \quad s=1, \ldots, S, j=1, \ldots, N, \\
p_{j k}, s_{j k}, c_{s j k}, u_{s j k} \geq 0, \\
\text { and } u_{s j k} \text { are integer, } \\
\text { and } x_{s j z v} \text { are binary, } \\
s=1, \ldots, S, \quad j=1, \ldots, N, \quad k=1, \ldots, M .
\end{gathered}
$$

The objective function (expression (1)) minimizes the sum of production costs, holding costs, and makespan costs. Constraints (2) represent the inventory balances. Constraints (3) ensure that the production time of each machine does not exceed its available capacity. In (4), the maximum of completion time of sublots on the last machine is used to define the makespan $\left(c_{\max }\right)$. Restrictions (5) ensure that in sum $p_{j k}$ items are produced from product $j$ on machine $k$. Constraints (6) ensure that sublots type is consistent. Constraints (7) and (8) ensure that the sublots of the same products do not overlap. Since intermingling is allowed, constraints (9) and (10) determine the sequence of sublots. No machine index is needed for binary variable $(x)$ in permutation flow shop. Restrictions (11) ensure that any sublot $s$ of any job $j$ begins processing on machine 1 after time zero. By replacing inequality constraint (7) with equality, the formulation can be adapted to case of no-wait flow shop. The previous formulation from (1) to (12) is for consistent sublots type. By adding (13), previous mathematical model can be adapted to equal sublots type. Consider

$$
\begin{gathered}
u_{s j k}=u_{(s+1) j k} \\
s=1, \ldots, S-1, \quad j=1, \ldots, N, \quad k=1, \ldots, M .
\end{gathered}
$$

The number of binary variables required can be calculated by $S^{2} \times\left(N^{2}-1\right)$.

2.1. No Intermingling between the Sublots of One (or More) of the J Products with the Other Products. This setting might be advantageous if the setup costs for one or more products are high. A quick approach for this setting is to use the model formulations (1) to (12) and equate the binary variables for the sublots of the product(s) that is (are) not allowed to intermingle. If all products are not allowed to intermingle, for a three-product example, this would be

$$
\begin{array}{r}
x_{s j 11}=x_{s j 21}=x_{s j 31}, \begin{array}{r}
s=1, \ldots, S, j=2,3 \\
\text { for first product, }
\end{array} \\
x_{s j 12}=x_{s j 22}=x_{s j 32}, \begin{array}{l}
s=1, \ldots, S, j=1,3 \\
\text { for second product, }
\end{array} \\
x_{s j 13}=x_{s j 23}=x_{s j 33}, \begin{array}{l}
s=1, \ldots, S, j=1,2 \\
\text { for third product }
\end{array}
\end{array}
$$

\section{Numerical Example}

In order to measure this model's performance, we use the model to test the following randomly generated problem: we have three types of products being processed on four machines. The number of sublots per product is three. Demands are 20,20, and 15 for products 1 to 3, respectively. Production costs are 10,15, and 12 for products 1 to 3 , respectively. Holding costs are 3, 4, and 3 for products 1 to 3. The maximum available capacity of machines is 400 time 
units for machines 1 to 4 . The beginning inventory is zero. Cost per unit time $(D)$ is equal to 5 . Table 1 summarizes the processing times of products on machines. The example has been solved using LINGO 12.0, a commercially available optimization software program, on a laptop computer with Intel core i5 $2410 \mathrm{~m}$ processor $2.3 \mathrm{GHz}$ with $4 \mathrm{~GB}$ of RAM.

3.1. Results of the Problem. LINGO solver defined the model of example as a mixed-integer linear problem (MILP) and used the branch and bound (B-and-B) method to solve it. The resulting formulation has a total of 169 variables and 691 constraints for consistent sublots with intermingling case. The solution was achieved after running the solver for 146 seconds. The results of the consistent sublots with intermingling case are as follows. Total costs are 3570, and makespan is equal to 170 . Sublot sizes are as follows: $u_{111}=$ $u_{112}=u_{113}=u_{114}=5, u_{211}=u_{212}=u_{213}=u_{214}=9$, $u_{311}=u_{312}=u_{313}=u_{314}=6, u_{121}=u_{122}=u_{123}=u_{124}=8$, $u_{221}=u_{222}=u_{223}=u_{224}=7, u_{321}=u_{322}=u_{323}=u_{324}=5$, $u_{131}=u_{132}=u_{133}=u_{134}=6, u_{231}=u_{232}=u_{233}=$ $u_{234}=4$, and $u_{331}=u_{332}=u_{333}=u_{334}=5$. Product quantities are $p_{11}=p_{12}=p_{13}=p_{14}=p_{21}=p_{22}=$ $p_{23}=p_{24}=20$ and $p_{31}=p_{32}=p_{33}=p_{34}=15$, with all inventory level or $S_{j k}=0$. Table 2 summarizes the completion times of each sublot. Figure 1 demonstrated the Gantt chart of this problem. The makespan is equal to total idle time on the last machine plus total processing time on the last machine [16]. For this example, in consistent sublots with intermingling setting, as demonstrated in Figure 1, makespan is equal to total idle time on machine number four which is 65 minutes plus total processing time on machine number four or 105 minutes, which will be equal to 170 minutes. Now, we solve this example for 8 different kinds of problems as follows: (1) consistent sublots with intermingling, (2) consistent sublots and no intermingling between sublots of the products (without intermingling), (3) equal sublots with intermingling, (4) equal sublots without intermingling, (5) no-wait consistent sublots with intermingling, (6) nowait equal sublots with intermingling, (7) no-wait consistent sublots without intermingling, and (8) no-wait equal sublots without intermingling. Tables 3, 4 and 5 summarized the results of these eight different lot streaming problems.

Columns 5 and 6 of Table 5 are achieved with the following formulations. $Z_{\text {best }}$ and the best makespan are 3570 and 170 which belong to consistent sublots with intermingling case. Comparison of total costs can be computed through $Z=\left(z-z_{\text {best }}\right) / z_{\text {best }} \times 100$ and comparison of make spans can be computed through $c_{\max }=c_{\max }-c_{\text {max }_{\text {best }}} / c_{\text {max }_{\text {best }}} \times 100$.

For instance, the makespan of consistent sublots with intermingling case is $11 \%$ better than makespan of consistent sublots without intermingling case. In equal sublots with and without intermingling cases, the production quantity and inventory will be $p_{1}=21, p_{2}=21$, and $p_{3}=15$ and $s_{14}=1$, $s_{24}=1$, and $s_{34}=0$, which causes additional costs. Therefore, in equal sublots cases, the increase in objective function (total cost) is not only due to the increase in makespan but also due to the increase in production quantity and inventory.
Figures 2, 3, and 4 are Gantt charts of these problems. Optimal sequence for schedule without lot streaming is 1-2-3 and the makespan is 2-4-5 (achieved through Johnson rules (SPT) [25]). The percentage of makespan reduction due to lot streaming in permutation flow shop is $30 \%$ (compared to the best makespan).

\section{Conclusion}

In this research, we developed the first mathematical model for integration of lot sizing and flow shop scheduling with lot streaming. We developed a mixed-integer linear model for multiple products lot sizing and lot streaming problems. Mixed-integer programming formulation was presented which enabled the user to find optimal production quantities, optimal inventory levels, and optimal sublot sizes, as well as optimal sequence simultaneously. We used a numerical example to show the practicality of the proposed model. We tested eight different lot streaming problems: (1) consistent sublots with intermingling, (2) consistent sublots and no intermingling between sublots of the products (without intermingling), (3) equal sublots with intermingling, (4) equal sublots without intermingling, (5) no-wait consistent sublots with intermingling, (6) no-wait equal sublots with intermingling, (7) no-wait consistent sublots without intermingling, and (8) no-wait equal sublots without intermingling. We showed that the best makespan can be achieved through the case of consistent sublots with intermingling. Since the increase in the number of binary variables and integrality restrictions, typically, make a lot streaming problem difficult to solve, the use of metaheuristic methods to deal with largescale problems deserves further study. The proposed model is adapted to consistent and equal sublot types. Extension of this model for variable sublot type could be another topic for further studies.

\section{Conflict of Interests}

The authors certify that there is no conflict of interests (considering both financial and nonfinancial gains) with any organization regarding the material discussed in the paper.

\section{Acknowledgment}

The authors would like to thank the anonymous referees for their invaluable comments and suggestions on an earlier draft of this paper.

\section{References}

[1] Z. Li and M. G. Ierapetritou, "Production planning and scheduling integration through augmented lagrangian optimization," Computers \& Chemical Engineering, vol. 34, no. 6, pp. 996-1006, 2010.

[2] J. Lasserre, "An integrated model for job-shop planning and scheduling," Management Science, vol. 38, no. 8, pp. 1201-1211, 1992.

[3] C. N. Potts and L. N. Van Wassenhove, "Integrating scheduling with batching and lot-sizing: a review of algorithms and 
complexity," Journal of the Operational Research Society, vol. 43, no. 5, pp. 395-406, 1992.

[4] F. Riane, A. Artiba, and S. Iassinovski, "An integrated production planning and scheduling system for hybrid flowshop organizations," International Journal of Production Economics, vol. 74, no. 1-3, pp. 33-48, 2001.

[5] H.-S. Yan, Q.-F. Xia, M.-R. Zhu, X.-L. Liu, and Z.-M. Guo, "Integrated production planning and scheduling on automobile assembly lines," IIE Transactions, vol. 35, no. 8, pp. 711-725, 2003.

[6] P. K. Palaniappan and N. Jawahar, "A genetic algorithm for simultaneous optimisation of lot sizing and scheduling in a flow line assembly," International Journal of Production Research, vol. 49, no. 2, pp. 375-400, 2011.

[7] H.-S. Yan and X.-D. Zhang, "A case study on integrated production planning and scheduling in a three-stage manufacturing system," IEEE Transactions on Automation Science and Engineering, vol. 4, no. 1, pp. 86-92, 2007.

[8] C. T. Ng, N. M. Matsveichuk, Y. N. Sotskov, and T. C. E. Cheng, "Two-machine flow-shop minimum-length scheduling with interval processing times," Asia-Pacific Journal of Operational Research, vol. 26, no. 6, pp. 715-734, 2009.

[9] N. M. Matsveichuk, Y. N. Sotskov, and F. Werner, "The dominance digraph as a solution to the two-machine flow-shop problem with interval processing times," Optimization, vol. 60, no. 12, pp. 1493-1517, 2011.

[10] R. Lundrigan, "What is this thing called OPT?" Production and Inventory Management, vol. 27, no. 2, pp. 2-11, 1986.

[11] A. A. Kalir and S. C. Sarin, "Evaluation of the potential benefits of lot streaming in flow-shop systems," International Journal of Production Economics, vol. 66, no. 2, pp. 131-142, 2000.

[12] M. Feldmann and D. Biskup, "Lot streaming in a multiple product permutation flow shop with intermingling," International Journal of Production Research, vol. 46, no. 1, pp. 197-216, 2008.

[13] W. Zhang, C. Yin, J. Liu, and R. J. Linn, "Multi-job lot streaming to minimize the mean completion time in m-1 hybrid flowshops," International Journal of Production Economics, vol. 96, no. 2, pp. 189-200, 2005.

[14] A. A. Kalir and S. C. Sarin, "Constructing near optimal schedules for the flow-shop lot streaming problem with sublotattached setups," Journal of Combinatorial Optimization, vol. 7, no. 1, pp. 23-44, 2003.

[15] S. C. Sarin and P. Jaiprakash, Flow Shop Lot Streaming Problems, Springer, New York, NY, USA, 2007.

[16] D. Trietsch and K. R. Baker, "Basic techniques for lot streaming," Operations Research, vol. 41, no. 6, pp. 1065-1076, 1993.

[17] D. Biskup and M. Feldmann, "Lot streaming with variable sublots: an integer programming formulation," Journal of the Operational Research Society, vol. 57, no. 3, pp. 296-303, 2006.

[18] J. H. Chang and H. N. Chiu, "A comprehensive review of lot streaming," International Journal of Production Research, vol. 43, no. 8, pp. 1515-1536, 2005.

[19] H.-N. Chiu, J.-H. Chang, and C.-H. Lee, "Lot streaming models with a limited number of capacitated transporters in multistage batch production systems," Computers \& Operations Research, vol. 31, no. 12, pp. 2003-2020, 2004.

[20] C. N. Potts and K. R. Baker, "Flow shop scheduling with lot streaming," Operations Research Letters, vol. 8, no. 6, pp. 297303, 1989.

[21] C. A. Glass and E. Possani, "Lot streaming multiple jobs in a flow shop," International Journal of Production Research, vol. 49, no. 9, pp. 2669-2681, 2011.
[22] C.-T. Tseng and C.-J. Liao, "A discrete particle swarm optimization for lot-streaming flowshop scheduling problem," European Journal of Operational Research, vol. 191, no. 2, pp. 360-373, 2008.

[23] S. Marimuthu, S. G. Ponnambalam, and N. Jawahar, "Evolutionary algorithms for scheduling $\mathrm{m}$-machine flow shop with lot streaming," Robotics and Computer-Integrated Manufacturing, vol. 24, no. 1, pp. 125-139, 2008.

[24] P. Brucker, Yu. N. Sotskov, and F. Werner, "Complexity of shopscheduling problems with fixed number of jobs: a survey," Mathematical Methods of Operations Research, vol. 65, no. 3, pp. 461-481, 2007.

[25] S. M. Johnson, "Optimal two-and three-stage production schedules with setup times included," Naval Research Logistics Quarterly, vol. 1, no. 1, pp. 61-68, 1954. 


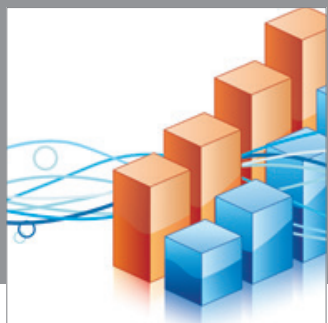

Advances in

Operations Research

mansans

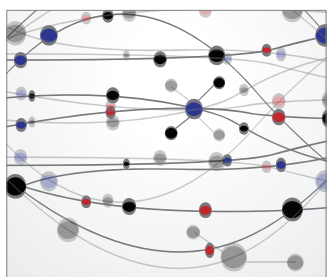

The Scientific World Journal
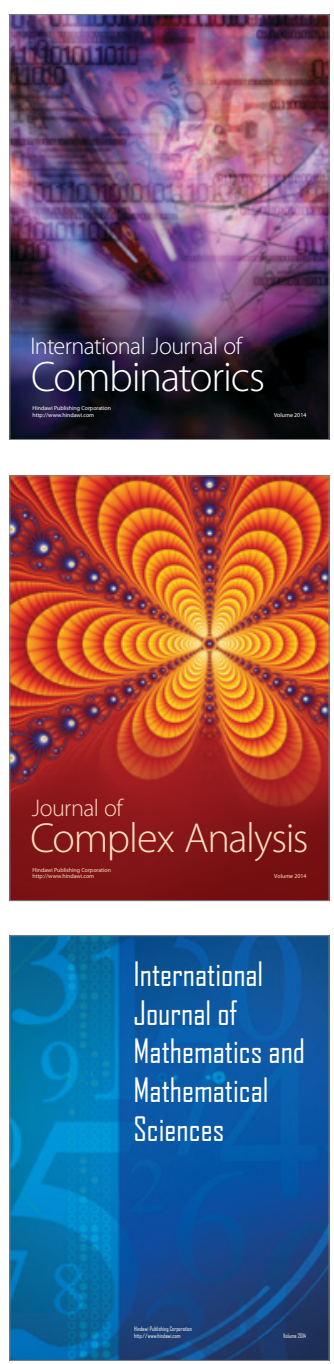
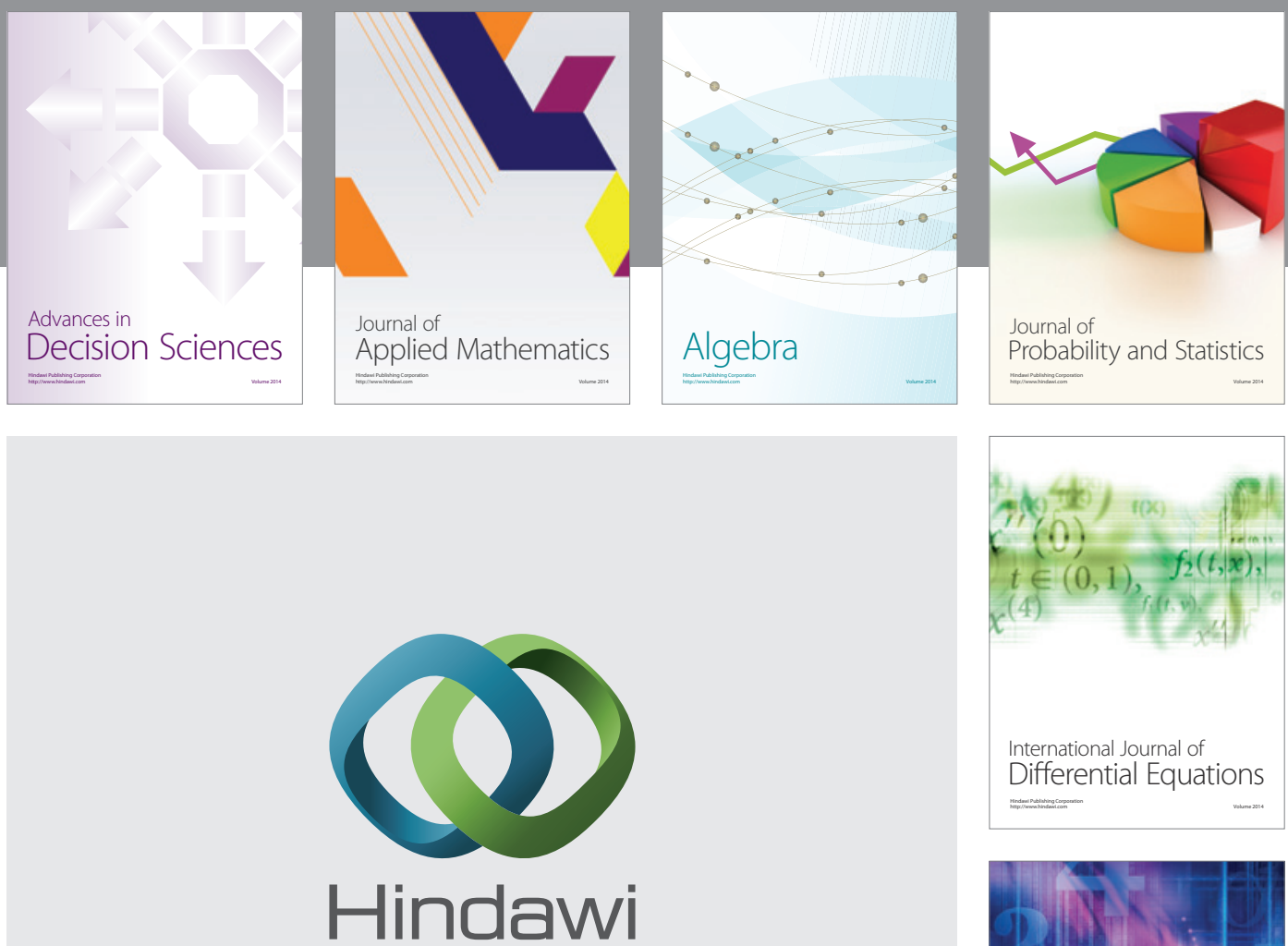

Submit your manuscripts at http://www.hindawi.com
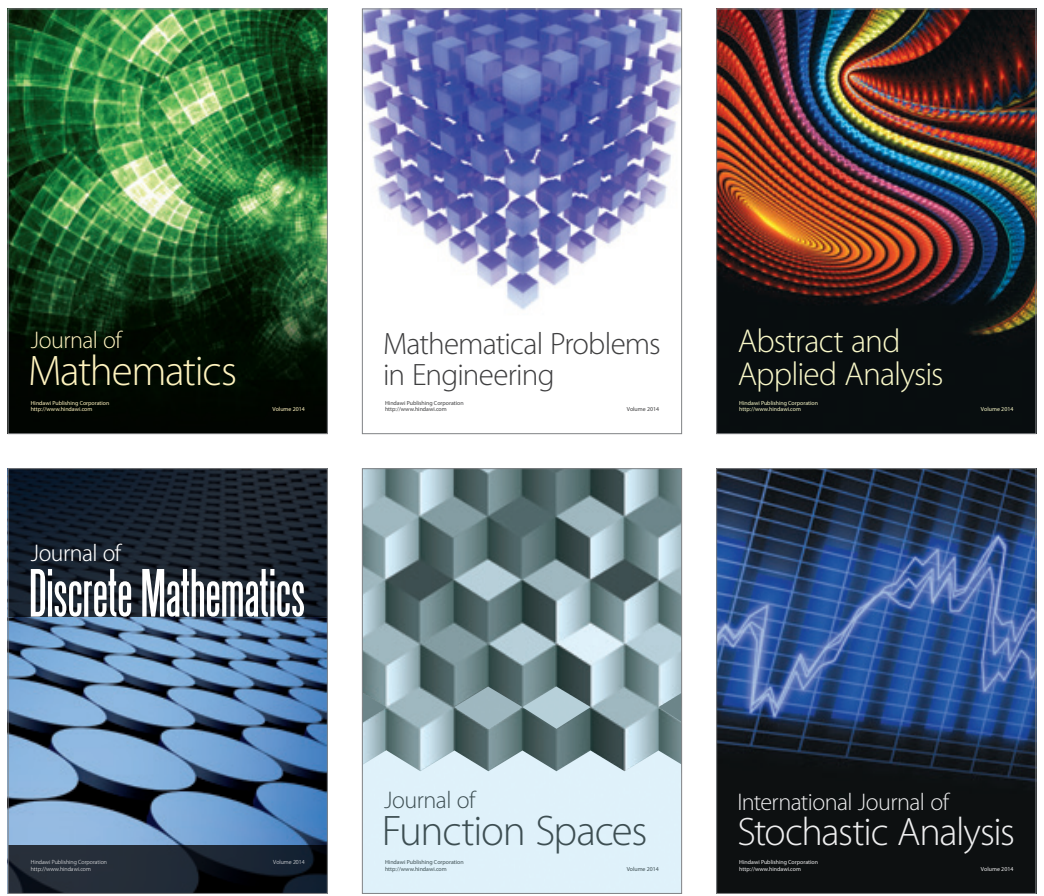

Journal of

Function Spaces

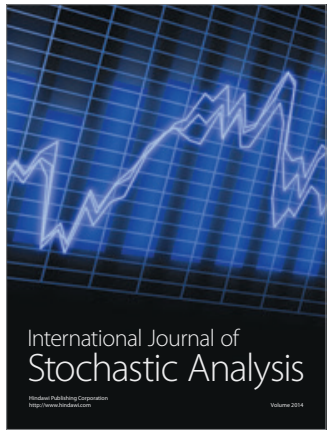

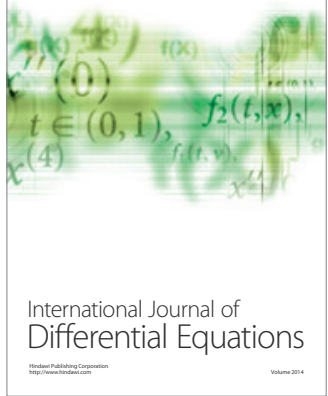
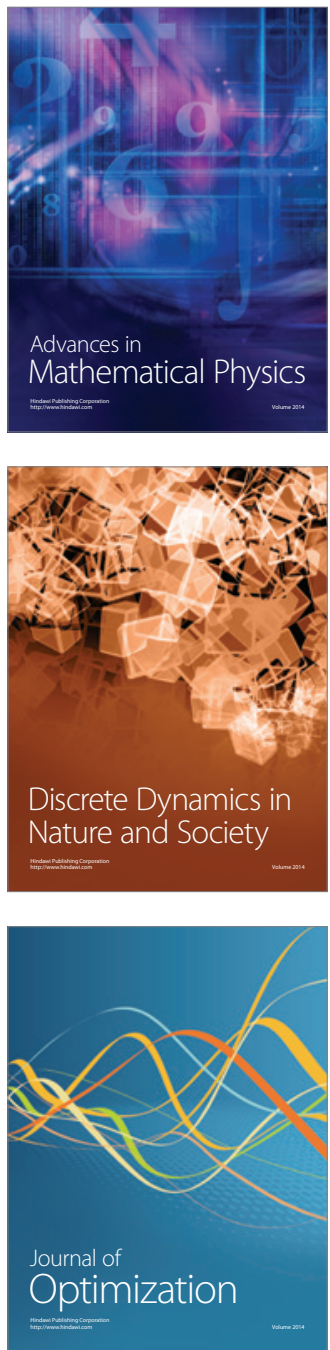